\title{
Article
}

\section{Apathy-Related Symptoms Appear Early in Parkinson's Disease}

\author{
Emmie Cohen ${ }^{1}$, Allison A. Bay ${ }^{2,3}$, Liang Ni ${ }^{2,3}$ and Madeleine E. Hackney ${ }^{2,3,4,5,6, *(\mathbb{C})}$ \\ 1 College of Arts and Sciences, Emory University, Atlanta, GA 30322, USA; emmie.taylor.cohen@emory.edu \\ 2 Department of Medicine, Division of Geriatrics and Gerontology, School of Medicine, Emory University, \\ 1841 Clifton Rd., Atlanta, GA 30329, USA; allison.bay@emory.edu (A.A.B.); liangni12@gmail.com (L.N.) \\ 3 Atlanta VA Center for Visual and Neurocognitive Rehabilitation, Decatur, GA 30033, USA \\ 4 School of Nursing, Emory University, Atlanta, GA 30329, USA \\ 5 Birmingham/Atlanta VA Geriatric Research Education and Clinical Center, Birmingham, AL 35233, USA \\ 6 Department of Rehabilitation Medicine, School of Medicine, Emory University, Atlanta, GA 30329, USA \\ * Correspondence: mehackn@emory.edu or madeleine.hackney@gmail.com
}

check for updates

Citation: Cohen, E.; Bay, A.A.; Ni, L.; Hackney, M.E. Apathy-Related Symptoms Appear Early in Parkinson's Disease. Healthcare 2022, 10, 91. https://doi.org/10.3390/ healthcare10010091

Academic Editors: Robbert Gobbens and Daniele Giansanti

Received: 29 September 2021

Accepted: 31 December 2021

Published: 4 January 2022

Publisher's Note: MDPI stays neutral with regard to jurisdictional claims in published maps and institutional affiliations.

Copyright: (C) 2022 by the authors. Licensee MDPI, Basel, Switzerland. This article is an open access article distributed under the terms and conditions of the Creative Commons Attribution (CC BY) license (https:// creativecommons.org/licenses/by/ $4.0 /)$.

\begin{abstract}
Background: Apathy, often-unrecognized in Parkinson's Disease (PD), adversely impacts quality-of-life (QOL) and may increase with disease severity. Identifying apathy early can aid treatment and enhance prognoses. Whether feelings related to apathy (e.g., loss of pleasure) are present in mild PD and how apathy and related feelings increase with disease severity is unknown. Methods: 120 individuals (M age: $69.0 \pm 8.2$ y) with mild (stages $1-2, n=71$ ) and moderate (stages $2.5-4 ; n=49)$ PD were assessed for apathy and apathy-related constructs including loss of pleasure, energy, interest in people or activities, and sex. Correlations were used to determine the association of apathy with apathy-related constructs. Regression models, adjusted for age, cognitive status, and transportation, compared groups for prevalence of apathy and apathy-related feelings. Results: Apathy-related constructs and apathy were significantly correlated. Apathy was present in one in five participants with mild PD and doubled in participants with moderate PD. Except for loss of energy, apathy-related constructs were observed in mild PD at a prevalence of $41 \%$ or greater. Strong associations were noted between all apathy-related constructs and greater disease severity. After adjustment for transportation status serving as a proxy for independence, stage of disease remained significant only for loss of pleasure and loss of energy. Conclusion: People with mild PD showed signs of apathy and apathy-related feelings. Loss of pleasure and energy are apathy-related feelings impacted by disease severity. Clinicians should consider evaluating for feelings related to apathy to enhance early diagnosis in individuals who might otherwise not exhibit psychopathology.
\end{abstract}

Keywords: Parkinson's disease; apathy; Hoehn and Yahr Scale; quality-of-life; non-motor symptoms; neuropsychiatric symptoms

\section{Introduction}

Parkinson's Disease (PD), the second most common neurodegenerative disease in the United States, involves dopamine depletion in the substantia nigra and ventral tegmental areas [1]. Reduced dopamine levels lead to Parkinson's motor symptoms and can result in the neuropsychiatric symptom, apathy. Characterized by loss of motivation, decreased activity, reduced enthusiasm, decreased interest, initiative, emotional indifference, a lack of concern, [2] and decreased motivation [3], apathy results in anhedonia (i.e., loss of pleasure) [4,5]. Traditionally, researchers have suggested a possible role of cognitive mechanisms in the expression of apathy. Apathy in people with PD is multidimensional and caused by dysfunction from different neural systems [2]. Impairments of distinct prefrontal cortex-basal ganglia circuits establish apathy subtypes. Apathy arises from a lesion and/or disruption of the prefrontal cortex-basal ganglia axis, which aids to control self-generated purposeful behavior [6,7]. Prefrontal cortex lesions are often observed in neurodegenerative diseases, such as, PD as well [8]. In early stages, some evidence shows 
apathy may be responsive to Levodopa treatment [9]. However, over time and even with gold-standard levodopa treatments, apathy is an often-intractable symptom of PD [8]. Currently, no strong level 1 evidence exists for treatment of apathy [10]. Early identification of apathy, especially in individuals with de novo PD, is vital to manage PD [11], given apathy results in decreased quality-of-life (QOL) [12] and may be a precursor or predictor of more severe disease [10] and cognitive impairment $[13,14]$.

Previous studies demonstrate the prevalence of apathy in PD to vary between 16.5\% [15] and $42 \%$ [16]. Although previous studies reported apathy in people with mild PD at a prevalence of $32 \%[17,18]$, currently, little information exists regarding the relationship between apathy and increasing disease severity. In a study using the Movement Disorders Society Unified Parkinson Disease Rating Scale (MDS-UPDRS) Part I (self-report of motor experiences of daily living) item 1.5 to measure apathy in PD, 104 out of 241 participants with mild-moderate PD (stages I-III) had apathy [19].

While neurologists address, consider and study akinesia and motor function, they may sometimes underestimate the importance of evaluating and treating apathy due to disease progression. More knowledge about the association between apathy and disease severity staging in PD would better allow clinicians to treat apathy symptoms and fine-tune participant-centered treatment of non-motor symptoms (NMS). No study has evaluated apathy comparing mild stages to moderate stages to determine the effect of increased disease severity. Further, psychological constructs that are related to apathy include fatigue, depression, and symptoms or feelings associated with depression, e.g., loss of pleasure, interest in people or activities, energy, and interest in sex [20]. Apathy may present alone or in concomitance with depression [6]. Apathy is strongly associated with depression, thus differentiating these syndromes remains challenging. As reported previously, up to 50\% of people with PD who also have apathy exhibit concomitant depression, which is more prevalent in individuals with greater disease severity [13]. While apathy is not a clinical criterion of depression, it may be a clinical expression of a depressed state. Apathy is not the consequence of depression in most neurological diseases [21,22]. Assessing apathyrelated constructs associated with depression could be useful in identifying indicators of apathy early in the PD process [10] by improving neuropsychiatric symptom treatment in earlier stages.

This study aimed to determine the association between apathy level, per the MDSUPDRS part I, [19] and stage of PD (early stages grouped into "mild" versus later stages grouped into "moderate" categories) in individuals from a large metro area in the southeastern United States. Given that apathy is likely related to dopamine depletion [23], we hypothesized that the percentage of participants with moderate PD (Hoehn and Yahr (HY) stages 2.5 , and 3) with some apathy would exceed the percentage of those with mild PD (HY stages 1, 1.5 and 2). Secondly, we wanted to determine the prevalence of feelings similar to apathy, which could enhance the early detection of apathy in PD. Therefore, we first investigated the validity of apathy-related constructs from the Beck Depression Questionnaire-II (i.e., the loss of pleasure, the loss of interest, the loss of energy, and the loss of interest in sex) with a Parkinson metric of apathy, the MDS-UPDRS part I item 1.5. Next, we compared mild and moderate groups on the prevalence of these apathy-related constructs. In analyses, we covaried for age, cognitive status and transportation status because of these covariates' strong relationship to worse neuropsychiatric symptoms [24-26]. Given that loss of pleasure, energy, interest in people and activities and interest in sex are possibly direct causes of or direct results of apathetic feelings [1,8], we hypothesized that the apathy-related constructs and apathy are strongly associated. We hypothesized a higher prevalence of apathy-related constructs than apathy itself in participants with mild PD. Because of the dopamine depletion associated with increasing disease severity [23], after adjustment for the important confounders mentioned above, this association would strengthen with increased disease stages for all apathy and apathy-related feelings. 


\section{Materials and Methods}

The Institutional Review Board at Emory University School of Medicine and the R\&D Committee of the Atlanta VA approved this work. Participants provided written informed consent before participating (IRB00080676; IRB00060613).

\subsection{Participants}

120 participants with Parkinson's Disease (PD) participated in the study. We recruited participants through the United States Department of Veterans Affairs (VA) registry, the VA Informatics, and Computing Infrastructure (VINCI) database, the Michael J. Fox finder website, the Movement Disorders Unit of Emory University, PD organizations' newsletters, support groups, and educational events and through word of mouth.

Participant Inclusion criteria follow. They were aged 40 years and older, had received a clinical diagnosis of PD from a Movement Disorders Society trained movement disorders neurologist, using standard, Movement Disorders society criteria. This diagnosis indicates that at the time of diagnosis eligible participants reported unilateral onset of symptoms, exhibited two of three cardinal signs (tremor, rigidity, and bradykinesia), and showed clear symptomatic benefits from antiparkinsonian medications, e.g., levodopa [27]. Participants were required to be able to walk at least three meters unassisted and were classified into HY stages I-IV [28]. Exclusion criteria follow: We excluded participants who reported major neurological disorders other than PD (e.g., previous stroke, traumatic brain injury, or peripheral neuropathies). Additionally, no one with untreated moderate or major depression could participate.

The scale of PD stage measurement is the Hoehn and Yahr Scale (HY), developed in 1967. The scale includes five stages and was recently adjusted to account for intermediate stages, adding stages 1.5 and 2.5 [29]. Stage 1 has unilateral involvement (minimal disability), Stage 1.5 has unilateral and axial involvement, stage 2 has bilateral involvement without balance impairment, stage 2.5 has mild bilateral disease with recovery on pull test, stage 3 has mild-moderate disability, impaired posture, and bilateral involvement, stage 4 represents those who are severely disabled, but these individuals still can stand unassisted, and stage 5 includes individuals with bed confinement [30]. Participants were grouped by disease severity, with $\mathrm{HY} \leq 2.5$ being classified as "mild" and HY $>2.5$ classified as "moderate." We determined these groupings because participants belonging to the "mild" group are considered to have no postural instability, while those in the group, "moderate" have postural instability. Postural instability is a strong indicator of an individual's level of independence, which is related to apathy and other neuropsychiatric symptoms.

\subsection{Assessment}

We used standard, valid and reliable tests in the assessments. Participants were administered a health questionnaire a week before their appointment. Medication status, including anti-parkinsonian medication, was gathered through this questionnaire and verified in an interview at the visit. At the appointment, participants were characterized for general ability to complete activities of daily living (ADLs) with the Composite Physical Function Index (CPF) [31,32]. Participants were tested while ON (i.e., participants were medicated with antiparkinsonian, (e.g., levodopa), treatment) for all assessments except for the Movement Disorders Society Unified Parkinson Disease Rating Scale part III (MDS-UPDRS-III), the rated motor exam, during which they were tested in the OFF (participants are off treatment) state, i.e., at least $12 \mathrm{~h}$ after having taken their last anti-parkinsonian medication. All participants were being treated by a movement disorders neurologist and were following a prescribed medication regimen. MDS-UPDRS is the recommended scale of the Movement Disorders Society for rating symptom severity in PD. Part I (self-report of motor experiences of daily living), II (self-report of non-motor experiences of daily living), III (observer rated motor exam), and IV (medication-related motor fluctuationsinterview) [33] were administered. The reliability of the MDS-UPDRS part I is supported as an outcome measure in PD studies [34]. Parts I and III were administered in the study. 
Part I assesses the non-motor impact of PD on patients' experiences of daily living. There are 13 questions. Part $1 \mathrm{~A}$ is administered by a rater (six questions) and focuses on complex behaviors.

\section{Covariates}

Age, cognitive status (as measured by the Montreal Cognitive Assessment (MoCA)), and transportation status (dichotomously determined as either transportation that was self-provided or the reliance on others for transportation) were used as important covariates in regression models to determine the relationship of disease stage (mild or moderate) with apathy and other outcome variables. These covariates were chosen for their strong association with neuropsychiatric symptoms. Previous studies reported an association between increased age, greater neuropsychiatric symptoms, impaired cognitive function and worsened quality-of-life (QOL) [24,25,35,36]. Individuals with apathy have been shown to be on average 3.3 years older than those without apathy [9]. Other reports demonstrated similar significant relationships between apathy and lower cognitive function $[3,8,15,16,24,37]$. Transportation status was chosen as a proxy for independence and because the examination of baseline clinical characteristics and demographics revealed differences between groups on this important covariate.

\subsection{Assessment of Apathy and Depression}

No agreed-upon gold standard for assessing apathy in PD exists [38,39]. Further validation must be included when a gold standard for assessing apathy is defined [2,40]. We used the apathy item derived from the MDS-UPDRS (1.5). The MDS-UPDRS is correlated with validated rating scales of QOL and functional disability [41]. There is a relationship between the MDS-UPDRS apathy construct and executive functioning, dopamine dysregulation syndrome, and cognitive impairments [42]. In the apathy item derived from the MDS-UPDRS interview section of Part I (question 1.5), the interviewer observes the level of spontaneous activity, motivation, assertiveness, and initiative and then rates the impact of reduced levels of performance in daily life and social interaction. The single item, Apathy (1.5), has been called an "easy to assess and suitable" item for screening for apathy and has been shown to have validity with the longer Lille Apathy Rating Scale, rho = 0.516, $p<0.001$ [43].

We also analyzed the fatigue item from the MDS-UPDRS (1.13) because of its highly correlated relationship with apathy [44-46]. These items are rated on a Likert scale from $0-4$, with zero signifying no symptoms and four being most severe. We used items from the Beck Depression Inventory-II (BDI-II) to determine the levels of apathy-related constructs. The BDI-II consists of 21 items related to depressive symptoms of how the participant is feeling over the previous two weeks. We performed targeted analyses focusing on the items that correlated most with apathy, which include the loss of the following: pleasure (BDI-II.4), interest (BDI-II.12), energy (BDI-II.15) and interest of sex (BDI-II.21). A higher score indicates more depression [47]. The cut-off for participants with moderate depression on the BDI-II is 18 [48]. Both the MDS-UPDRS and the BDI-II are not limited by floor and ceiling effects because psychometric studies showed fewer than $15 \%$ of all participants achieved highest or lowest scores [34,49].

Participants were also administered the Geriatric Depression Scale, as well as the complete BDI-II scale.

\subsection{Neuropsychological Assessment}

Cognitive assessments included the Montreal Cognitive Assessment (MoCA), a measure of global cognition [50].

\subsection{Statistical Analysis}

Data were entered and cross-checked for quality assurance. The probability of having apathy in mild and moderate disease stages was estimated [17-19], and these probabilities 
were used to estimate the expected prevalence of apathy in our own sample between mild and moderate stage participants. Our analysis revealed that our sample of 120 individuals has nearly $80 \%$ (77\%) power to detect differences in the proportion of individuals with apathy between mild and moderate stage PD groups at the 95\% confidence level. We acknowledge this $77 \%$ does not reach $80 \%$ power which is generally considered acceptable to avoid type 2 error. Therefore, findings from this pilot study should be interpreted very cautiously. Future work is necessary to confirm the findings presented here.

We binned participants into the following categories of PD: HY stages 1-2 (Mild) and 2.5-4 (Moderate). To characterize the sample, we calculated descriptive statistics, including levodopa equivalency dosage for a subset of participants for whom data were available, and using the method as published by Tomlinson et al. (2010) [51]. We analyzed demographic and clinical characteristics for differences between groups using independent $t$-tests and chi-square tests as appropriate. Spearman correlations assessed associations between the MDS-UPDRS Part I and BDI-II variables.

Because of the skewed distribution of responses with high frequencies of zero responses across items, we dichotomized the variables: Apathy (MDS-UPDRS 1.5), Loss of Pleasure (BDI-II.4), Loss of Interest in People or Activities (BDI-II.12), and Loss of Interest in Sex (BDI-II.21) into variables with two categories (0: "none", >0: "some"). In the variable without high frequencies of zeros: Loss of Energy (BDI-II.15), we dichotomized according to a reasonable distribution of high versus low on the scale into two groups (0-1: "No/Slight Loss"; 2-3: "Mild/Severe Loss"). We dichotomized the fatigue (MDS-UPDRS 1.13) variable into two categories (0-1: "Normal/Slight/Mild"; 2-4: "Moderate/Severe").

To identify how group status (level of disease severity) affected levels on the apathy / fatigue-related constructs, we used multivariate logistic regression models for the dichotomous variables. Model 1 adjusted for age, model 2 adjusted for age and MoCA, and model 3 adjusted for age, MoCA, and transportation. Transportation was adjusted because of the distribution noted in the groups. The independent variables used in our models included group, age, MoCA, and transportation. The dependent variables were the dichotomized BDI-II items. The odds ratios (OR) $\pm 95 \%$ confidence interval (CI) expressed the association between the apathy-related constructs and the severity of HY stages. We performed analyses using R (R Core Team 2017, Vienna, Austria).

\section{Results}

The 120 individuals with Parkinson's Disease (PD) were classified into Hoehn and Yahr Scale (HY) stages 1-2, "mild," $n=71$ (stage 1, $n=7$, stage 1.5, $n=15$, stage 2, $n=49$ ); or HY stages 2.5-4 (stage 2.5, $n=17$, stage 3, $n=29$, stage $4, n=3$ ), “moderate," $n=49$. Table 1 presents the participant characteristics. The sample was $25 \%$ non-white, and for 26 participants who reported Levodopa dosage, the sample took an estimated $616 \mathrm{mg}$ of L-dopa daily. The moderate HY group was older, and more at risk for loss of function, had PD longer, had higher BDI-II scores, (but not GDS scores), had lower MoCA scores, were slightly more likely to live in senior living, were less likely to transport themselves, left their house less frequently, took more prescribed medications and were more likely to use an assistive device than the mild group. BDI-II values are presented in Table 1 ranging from $\mathrm{M}=11.4-15.5(8.5,8.7)$, indicating mild depression among some participants. GDS scores are also presented.

Correlations between apathy-related items.

Table 2 presents the associations between the scores of apathy-related constructs on the MDS-UPDRS Part I and the BDI-II in a correlation matrix. We noted significant, moderate positive correlations between apathy, loss of pleasure, loss of interest in people or activities, and loss of interest in sex. 
Table 1. Demographic characteristics of participants with mild vs. moderate stages of Parkinson's disease.

\begin{tabular}{|c|c|c|c|c|c|}
\hline & & Whole Sample & Mild (1-2) & Moderate (2.5-4) & $p$ \\
\hline $\mathrm{N}$ & & 120 & 71 & 49 & \\
\hline Age & & $68.98 \pm 8.2$ & $66.89 \pm 7.9$ & $71.98 \pm 7.8$ & 0.001 \\
\hline \multirow[t]{7}{*}{$\mathrm{H} \& \mathrm{Y}, \mathrm{N}(\%)^{\wedge}$} & 1 & $7(5.8)$ & $7(9.9)$ & $0(0)$ & $<0.001$ \\
\hline & 1.5 & $15(12.5)$ & $15(21.1)$ & $0(0)$ & \\
\hline & 2 & $49(40.8)$ & $49(69)$ & $0(0)$ & \\
\hline & 2.5 & $17(14.2)$ & $0(0)$ & $17(34.7)$ & \\
\hline & 3 & $29(24.2)$ & $0(0)$ & $29(59.2)$ & \\
\hline & 4 & $3(2.5)$ & $0(0)$ & $3(6.1)$ & \\
\hline & & $36.24 \pm 13.23$ & $29.73 \pm 11.29$ & $45.67 \pm 9.73$ & $<0.001$ \\
\hline \multicolumn{6}{|l|}{$\begin{array}{l}\text { MDS-UPDRS III } \\
\text { (score) }\end{array}$} \\
\hline Education (years) & & $16.27 \pm 2.5$ & $16.61 \pm 2.6$ & $15.69 \pm 2.3$ & 0.098 \\
\hline $\begin{array}{l}\text { Body Mass Index } \\
\qquad\left(\mathrm{kg} / \mathrm{m}^{2}\right)\end{array}$ & & $26.59 \pm 5.2$ & $26.87 \pm 5$ & $26.18 \pm 5.5$ & 0.480 \\
\hline No. Comorbidities & & $3.45 \pm 1.9$ & $3.36 \pm 1.9$ & $3.58 \pm 1.8$ & 0.519 \\
\hline $\begin{array}{l}\text { Composite Physical } \\
\text { Function (/24) } \\
\text { Number of Medication }\end{array}$ & & $\begin{array}{l}18.25 \pm 5.4 \\
4.88 \pm 3.62\end{array}$ & $\begin{array}{c}20.7 \pm 3.5 \\
4.78 \pm 2.93 \\
\end{array}$ & $\begin{array}{l}14.62 \pm 5.8 \\
7.03 \pm 4.33 \\
\end{array}$ & $\begin{array}{l}<0.001 \\
<0.001\end{array}$ \\
\hline Time with PD (y) & & $6.96 \pm 5$ & $5.38 \pm 3.7$ & $9.24 \pm 5.8$ & $<0.001$ \\
\hline MoCA Score (/30) & & $24.8 \pm 4.2$ & $26.3 \pm 2.8$ & $22.8 \pm 5.0$ & $<0.001$ \\
\hline $\begin{array}{l}\text { BDI-II total score } \\
\text { Geriatric Depression } \\
\text { Scale (GDS) }\end{array}$ & & $\begin{array}{c}12.9 \pm 8.7 \\
4.15 \pm 3.52\end{array}$ & $\begin{array}{c}11.4 \pm 8.7 \\
3.87 \pm 3.30 \\
\end{array}$ & $\begin{array}{c}15.5 \pm 8.5 \\
4.61 \pm 3.84 \\
\end{array}$ & $\begin{array}{l}\mathbf{0 . 0 1 0} \\
0.347\end{array}$ \\
\hline \multirow[t]{3}{*}{ Sex, N (\%)^ } & & & & & 0.982 \\
\hline & Men & $77(64.2)$ & $45(63.4)$ & $32(65.3)$ & \\
\hline & Women & $43(35.8)$ & $26(36.6)$ & $17(34.7)$ & \\
\hline \multirow[t]{4}{*}{ Race $(\mathrm{B} / \mathrm{W}), \mathrm{N}(\%)^{\wedge}$} & & & & & 0.471 \\
\hline & Black & $22(18.3)$ & $12(16.9)$ & $10(20.4)$ & \\
\hline & Other & $9(7.5)$ & $7(9.9)$ & $2(4.1)$ & \\
\hline & White & $89(74.2)$ & $52(73.2)$ & $37(75.5)$ & \\
\hline \multirow[t]{3}{*}{ House Type, N (\%)^ } & & & & & 0.020 \\
\hline & $\begin{array}{l}\text { Assisted/senior } \\
\text { living }\end{array}$ & $10(8.4)$ & $2(2.8)$ & $8(16.7)$ & \\
\hline & Self/independently & 109 (91.6) & $69(97.2)$ & $40(83.3)$ & \\
\hline \multirow[t]{3}{*}{ Transportation, N (\%)^ } & & & & & $<0.001$ \\
\hline & Other & $33(27.7)$ & $7(9.9)$ & $26(54.2)$ & \\
\hline & Self & $86(72.3)$ & $64(90.1)$ & $22(45.8)$ & \\
\hline \multirow[t]{5}{*}{ Leave House, N (\%)^ } & & & & & $<0.001$ \\
\hline & 1-2 times/week & $10(8.5)$ & $2(2.8)$ & $8(17)$ & \\
\hline & 1 time/week & $1(0.8)$ & $0(0)$ & $1(2.1)$ & \\
\hline & 3-4 times/week & $37(31.4)$ & $13(18.3)$ & $24(51.1)$ & \\
\hline & Daily & $70(59.3)$ & $56(78.9)$ & $14(29.8)$ & \\
\hline
\end{tabular}


Table 1. Cont.

\begin{tabular}{|c|c|c|c|c|c|}
\hline & & Whole Sample & Mild (1-2) & Moderate (2.5-4) & $p$ \\
\hline \multirow[t]{4}{*}{$\begin{array}{l}\text { Use of Assistive } \\
\text { Device, } N(\%) \wedge\end{array}$} & & & & & $<0.001$ \\
\hline & No & $55(46.6)$ & $44(62.9)$ & $11(22.9)$ & \\
\hline & Yes & $63(53.4)$ & $26(37.1)$ & $37(77.1)$ & \\
\hline & $\begin{array}{l}\text { Partici } \\
\text { Catego } \\
\text { and M } \\
\text { Chi-sq } \\
p<0.05\end{array}$ & $\begin{array}{l}\text { e Characteristics. C } \\
\text { e values are presen } \\
\text { aps, } p \text { values were } \\
\text { s used for categoric }\end{array}$ & $\begin{array}{l}\text { us variables vo } \\
\mathrm{J}(\%) \text { denoted } \\
\text { ed with an inc } \\
\text { bles. Bolded }\end{array}$ & $\begin{array}{l}\text { re presented as Mean } \\
\text { To determine differe } \\
\text { ent } t \text {-test for continu } \\
\text { are significant. Signif }\end{array}$ & $\begin{array}{l}\text { dard Deviation. } \\
\text { ween the Mild } \\
\text { iables, and the } \\
\text { evel was set at }\end{array}$ \\
\hline
\end{tabular}

Table 2. Correlations between apathy and apathy-related variables.

\begin{tabular}{cccccccc}
\hline \multirow{2}{*}{ Items } & $\begin{array}{c}\text { Apathy (MDS- } \\
\text { UPDRS 1.5) }\end{array}$ & $\begin{array}{c}\text { Fatigue (MDS- } \\
\text { UPDRS 1.13) }\end{array}$ & $\begin{array}{c}\text { Loss of } \\
\text { Pleasure } \\
\text { (BDI-II.4) }\end{array}$ & $\begin{array}{c}\text { Loss of Interest in } \\
\text { People or Activities } \\
\text { (BDI-II.12) }\end{array}$ & $\begin{array}{c}\text { Loss of } \\
\text { Energy } \\
\text { (BDI-II.15) }\end{array}$ & $\begin{array}{c}\text { Loss of } \\
\text { Interest in Sex } \\
\text { (BDI-II.21) }\end{array}$ \\
\hline $\begin{array}{c}\text { Apathy (MDS- } \\
\text { UPDRS 1.5) }\end{array}$ & $p$ & $1 *$ & $0.39 *$ & $0.33^{*}$ & $0.31 *$ & 0.16 & $0.25 *$ \\
\hline \multicolumn{7}{c}{${ }^{*}$ * Values were Spearman correlation coefficients. }
\end{tabular}

Apathy items.

Table 3 presents the associations between apathy/apathy-related constructs and PD staging along with the corresponding OR. Models 2 and 3 are discussed here. Approximately $21 \%$ of participants with mild PD reported apathy, and $44 \%$ of participants with moderate PD reported apathy. Model 2 (adjusted for age and MoCA) shows the odds of reporting apathy to be 3.74 times greater among moderate participants than participants with mild PD, and that in Model 3 (adjusted for age, MoCA, and transportation) the odds fell to 2.47 times greater and were not significant after controlling for transportation status. Moreover, the analyses demonstrated that transportation status removed the significance of disease stage on most of the related feelings.

Approximately half of the sample in both groups reported fatigue, and no models were significant for effect of PD stage. Fifty-four percent of participants with mild PD and $78 \%$ of participants with moderate PD reported loss of pleasure. The odds of reporting loss of pleasure were 5.11 times greater among participants with moderate PD than participants with mild PD after controlling for both age and MoCA (Model 2), remaining significant after controlling for transportation in model 3.

Forty-one percent of participants with mild PD and 57\% of participants with moderate PD reported loss of interest in people and activities. The odds of reporting loss of interest in people and activities were 2.14 times greater in participants with moderate PD than participants with mild PD after controlling for age and MoCA score (Model 2) but were not significant after transportation was added (Model 3).

Eleven percent of participants with mild PD and $22 \%$ of participants with moderate PD reported loss of energy. The odds of having loss of energy were 3.59 times greater among participants with moderate PD (Model 2), increasing to 5.06 times greater after controlling for age, MOCA and mode of transportation (Model 3).

Forty-seven percent of participants with mild PD and $65 \%$ of participants with moderate PD reported a loss of interest in sex. The odds of participants with moderate PD having greater loss of interest in sex than participants with mild PD were not significant in any of the models after controlling for age, MOCA and transportation (Table 3).

Supplementary (Table S1) presents mean and standard deviations for ordinal outcome variables. 
Table 3. Comparison of outcome variables between the mild group and moderate group.

\begin{tabular}{|c|c|c|c|c|c|c|c|c|c|c|c|}
\hline & & $\begin{array}{l}\text { Mild } \\
(1-2)\end{array}$ & $\begin{array}{l}\text { Mod. } \\
(2.5-4)\end{array}$ & Unadj & & Model 1 & & Model 2 & & Model 3 & \\
\hline Items & & N (\%) & N (\%) & $\begin{array}{c}\text { OR } \\
\text { Moderate } \\
\text { vs. Mild } \\
(95 \% \text { CI })\end{array}$ & $p$ & $\begin{array}{c}\text { OR } \\
\text { Moderate } \\
\text { vs. Mild } \\
(95 \% \text { CI })\end{array}$ & $p$ & $\begin{array}{c}\text { OR } \\
\text { Moderate } \\
\text { vs. Mild } \\
(95 \% \text { CI })\end{array}$ & $p$ & $\begin{array}{c}\text { OR } \\
\text { Moderate } \\
\text { vs. Mild } \\
(95 \% \text { CI })\end{array}$ & $p$ \\
\hline \multirow[t]{2}{*}{$\begin{array}{c}\text { Apathy } \\
\text { (MDS- } \\
\text { UPDRS } \\
1.5 \text { ) }\end{array}$} & No apathy & $56(79)$ & $27(56)$ & $\begin{array}{c}2.90 \\
(1.31,6.61)\end{array}$ & 0.010 & $\begin{array}{c}3.34 \\
(1.43,8.15)\end{array}$ & 0.006 & $\begin{array}{c}3.74 \\
(1.52,9.6)\end{array}$ & 0.005 & $\begin{array}{c}2.47 \\
(0.91,6.73)\end{array}$ & 0.075 \\
\hline & $\begin{array}{l}\text { With } \\
\text { apathy }\end{array}$ & $15(21)$ & $21(44)$ & & & & & & & & \\
\hline \multirow[t]{2}{*}{$\begin{array}{c}\text { Fatigue } \\
\text { (MDS- } \\
\text { UPDRS } \\
1.13) \\
\end{array}$} & $\begin{array}{l}\text { Normal/ } \\
\text { Slight/Mild }\end{array}$ & $38(54)$ & $19(41)$ & $\begin{array}{c}1.69 \\
(0.8,3.62)\end{array}$ & 0.173 & $\begin{array}{c}1.96 \\
(0.89,4.46)\end{array}$ & 0.1 & $\begin{array}{c}1.96 \\
(0.84,4.69)\end{array}$ & 0.123 & $\begin{array}{c}1.44 \\
(0.57,3.62)\end{array}$ & 0.438 \\
\hline & $\begin{array}{l}\text { Moderate/ } \\
\text { Severe }\end{array}$ & $32(46)$ & $27(59)$ & & & & & & & & \\
\hline \multirow[t]{2}{*}{$\begin{array}{c}\text { Loss of } \\
\text { Pleasure } \\
\text { (BDI-II.4) }\end{array}$} & No & $33(46)$ & $11(22)$ & $\begin{array}{c}3.0 \\
(1.35,7.02)\end{array}$ & 0.008 & $\begin{array}{c}4.93 \\
(2.02,13.12)\end{array}$ & 0.001 & $\begin{array}{c}5.11 \\
(1.96,14.76)\end{array}$ & 0.001 & $\begin{array}{c}4.75 \\
(1.72,14.58)\end{array}$ & 0.004 \\
\hline & Yes & $38(54)$ & 38 (78) & & & & & & & & \\
\hline \multirow[t]{2}{*}{$\begin{array}{c}\text { Loss of } \\
\text { Interest in } \\
\text { People or } \\
\text { Activities } \\
\text { (BDI- } \\
\text { II.12) }\end{array}$} & No & $42(59)$ & $21(43)$ & $\begin{array}{c}1.93 \\
(0.93,4.08)\end{array}$ & 0.080 & $\begin{array}{c}2.30 \\
(1.05,5.17)\end{array}$ & 0.04 & $\begin{array}{c}2.14 \\
(0.93,5.08)\end{array}$ & 0.077 & $\begin{array}{c}2.34 \\
(0.95,5.98)\end{array}$ & 0.068 \\
\hline & Yes & $29(41)$ & $28(57)$ & & & & & & & & \\
\hline \multirow[t]{2}{*}{$\begin{array}{c}\text { Loss of } \\
\text { Energy } \\
\text { (BDI- } \\
\text { II.15) }\end{array}$} & $\begin{array}{c}\text { No/Slight } \\
\text { loss }\end{array}$ & $63(89)$ & $38(78)$ & $\begin{array}{c}2.28 \\
(0.85,6.37)\end{array}$ & 0.105 & $\begin{array}{c}3.15 \\
(1.09,9.75)\end{array}$ & 0.038 & $\begin{array}{c}3.59 \\
(1.17,11.69)\end{array}$ & 0.027 & $\begin{array}{c}5.06 \\
(1.54,17.95)\end{array}$ & 0.009 \\
\hline & $\begin{array}{l}\text { Mild/severe } \\
\text { loss }\end{array}$ & $8(11)$ & $11(22)$ & & & & & & & & \\
\hline \multirow[t]{2}{*}{$\begin{array}{l}\text { Loss of } \\
\text { Interest in } \\
\text { Sex (BDI- } \\
\text { II.21) }\end{array}$} & No & $37(53)$ & $17(35)$ & $\begin{array}{c}2.11 \\
(1,4.54)\end{array}$ & 0.052 & $\begin{array}{c}2.40 \\
(1.09,5.47)\end{array}$ & 0.033 & $\begin{array}{c}2.19 \\
(0.95,5.26)\end{array}$ & 0.071 & $\begin{array}{c}1.73 \\
(0.7,4.37)\end{array}$ & 0.235 \\
\hline & Yes & $33(47)$ & $32(65)$ & & & & & & & & \\
\hline
\end{tabular}

\section{Discussion}

In this cohort, apathy prevalence in moderate stages (44\%) was twice that of mild stages. All apathy-related constructs were strongly associated with apathy except for loss of energy. In contrast to apathy prevalence, in mild stages of PD, loss of pleasure, interest in people or activities, and sex were highly prevalent at $>41 \%$. Disease staging impacted apathy and related feelings, given that over $50 \%$ of the moderate group reported fatigue, loss of interest in people or activities, loss of interest in sex, and/or loss of pleasure. However, with all three covariates controlled for in Model 3, the premise that apathy increased with disease severity is not fully supported by our data, disagreeing with some previous work that did not control for these covariates [52]. After being added to the model, transportation status was an impactful covariate, given that stage of disease effect was no longer significant for apathy, loss of interest in people/activities, loss of interest in sex, and fatigue. In contrast, odds remained significant for loss of pleasure and loss of energy. 


\subsection{Apathy-Related Feelings and Early Disease Detection}

A novel contribution of this work was demonstrating the construct validity of apathyrelated constructs from a non-PD-specific metric, BDI-II, to apathy as measured by a PD-specific metric, MDS-UPDRS Part I, the apathy item. Adding to previous work, we found that loss of pleasure, interest in people or activities, and interest in sex were strongly correlated to apathy and fatigue [53-55]. All BDI-II items, except the loss of energy, were correlated to apathy within our study. Apathy-related constructs and feelings may help with the early detection of apathy and related sequelae. Apathy, not depression, is associated with increased cortical amyloidopathy in PD, agreeing with work showing a relationship with cognitive decline [56]. Cortical and striatal $\beta$-amyloidopathy has been previously noted in apathetic PD participants compared to non-apathetic PD participants [57]. Executive cognitive dysfunction is most apparent in apathetic PD participants when apathy has been evaluated and determined based on participant emotional, interest, and motivation responses [8]. Previous research reported a clear negative correlation between apathy and cognitive status. Impaired cognition has been associated with increased apathy at even early stages [52]. Therefore, apathy may be an early biomarker for cognitive impairments in PD [52] and must be identified as soon as possible.

\subsection{High Prevalence of Apathy-Related Feelings in Mild Stages}

The high prevalence of several apathy-related feelings in mild stages could be utilized as an indicator of likely development of apathy in moderate stages. Future research will further investigate the relationship between these feelings and the progression to apathy in moderate stages. Indications of related feelings would possibly serve as precursors to the neuropsychiatric symptom of apathy and its related symptomatology [58].

\subsection{People with Moderate PD Reported Higher Odds of Experiencing Loss of Pleasure and Loss of Energy than People with Mild PD}

Currently, the relationship between apathy and anhedonia is unclear in PD because the Diagnostic and Statistical Manuel of Mental Disorders-IV (DSM-IV) does not distinguish between them [59]. Previous work reported high anhedonia levels in apathetic compared to non-apathetic people with PD [8]. The high odds of loss of pleasure and loss of energy in our findings may be universal experiences in moderate stages, regardless of age, cognition, and transportation. The loss of energy most likely represents a symptom of depression [60], which is related to apathy but has its own pathological and clinical course.

\subsection{Lack of Transportation and Independence May Contribute to Apathy}

We found a relationship between disease severity and apathy using models with (a) no covariates, (b) controlling for age only and c) for both age and cognition, which is consistent with previous studies [3,24,44,61-63]. Interestingly, our analysis demonstrated that the inclusion of transportation status removed the significance of disease stage on apathy and most related feelings. Other work has also reported no relationship between disease severity and apathy, though this work did not examine transportation status as a proxy for independence [43]. Transportation is a fundamental human necessity for all ages and has been linked to autonomy, independence, and quality-of-life (QOL) [64-66]. Regarding health-related QOL, self-evaluated autonomy is a key predictor and important aspect of neurodegenerative disease course, for example, that of PD [67]. Autonomy is reduced by the physical and emotional burdens presented to the participant and their family during the disease course [68]. Driving, especially in the United States, is regularly linked to autonomy and symbolizes personal independence for adults [64,69]. A high level of cognition, motor functioning, and independent mobility is necessary to drive a vehicle [70]. Transportation is related to independence as it represents a basic human need to get from place A to B [65]. As such, the independence that is lost with inability to provide one's own transportation may be highly associated with feelings of apathy and far more important to one's mood than even the motor impairments experienced by the individual with moderate PD. Our 
findings indicate that independence is highly impactful on apathy and related feelings. While transportation dependence seems to increase with age, age may not be the ultimate explanation. Rather, poor driving-related abilities due to conditions such as PD may better explain patterns of transportation dependence [71]. Covarying for transportation status allowed us to remove variance related to participants' state of independence. Individuals with limited independence must depend on caregivers and others for everyday functioning, which is greatly associated with decreased quality of life [72]. More research is necessary to investigate the relationship between independence in PD and reports of apathy.

\subsection{Understanding Fatigue May Be Important in People with Apathetic PD}

Our findings support a relationship between apathy and fatigue. Only about 1 in 10 participants reported a loss of energy in both groups, though more than half of the sample reported fatigue. The PD-centric metric of fatigue from the MDS-UPDRS was reported in approximately half of our sample, with early and late PD reporting roughly the same prevalence. These findings agree with previous work that showed fatigue present in $44 \%$ of the total PD population [73] and apathy and fatigue presence in all stages of PD [74,75].

\subsection{Limitations}

Limitations in this study include using the single item from the MDS-UPDRS as a measurement of apathy. Other apathy scales, such as the Starkstein Apathy Scale and Lille Apathy Rating Scale, are more accurate measures of apathy but were unavailable for this secondary data analysis. However, the MDS-UPDRS is the gold standard scale used by neurologists to evaluate people with PD. The apathy item within the MDS-UPDRS comes from the original motivation/initiative item in the UPDRS [76], and this item has been shown to have clinical utility for screening and high correlation with a more complete apathy scale [43] By dichotomizing the Apathy item, we can only determine if apathy is mildly or moderately present. Additional valid and standard measures of apathy should be included in apathy specific research moving forward. However, this work was concerned with the clinical utility of the scales used here, given the purpose of this work was to identify other items that will probe and screen for apathy in people with early PD. Akinesia levels were not examined in this study. Future work will examine the relationship between levels of bradykinesia specifically and reported apathy. Our findings should be interpreted with caution due to the large CI (95\%) used due to the small sample size and high dispersion of data. We excluded participants with major neurological disorders, which limits generalizability. Larger sample sizes are necessary for future studies to be able to make more definitive conclusions. Further, very few participants $(n=2)$ were stage IV, and no participants were stage $\mathrm{V}$; thus, no conclusions about severe PD and apathy can be made. We used transportation status as a proxy for independence, and because of observed differences between groups; however, other measures may be more suitable for measuring independence for future research examining the relationship between independence, disease severity and apathy.

\section{Conclusions}

More individuals with moderate PD than mild individuals report apathy; however, their disease level does not explain why they report apathy. Independence levels, age, and cognitive status may account for apathy more than the disease stage itself. While a relationship between disease severity and apathy/apathy-related constructs exists when controlling for age and cognition, most of the significant effects of the disease stage disappear after controlling for transportation. Our results contradict the postulation that apathy increases with disease severity, which has been the overall consensus from several previous studies that did not adjust for our covariates.

In our participants with mild PD, the data show the prevalence of apathy-related constructs of fatigue, loss of pleasure, loss of interest in people or activities, and loss 
of interest in sex at greater than $41 \%$. This information is important because previous studies have presented data that posit apathy as a possible early expression of executive impairment and cognitive processing in PD [77]. Early identification of apathy, specifically in de novo PD participants, is essential for optimal clinical management [6]. Participants are less likely to report severe cognitive deficits in mild versus moderate stages of PD [26,78]. Identifying apathetic signs early in PD should receive greater attention from neurologists following these participants and drive more referrals to mental health specialists.

Several apathy-related neuropsychiatric symptoms may be detected in people with mild PD, while apathy itself appears to be reported by those with moderate PD more. The quality-of-life (QOL) of individuals with PD may be enhanced with the early detection of apathy [59]. Increasing the methods including specifically evaluating the participant for loss of energy and loss of pleasure, may help identify people with PD who are at risk of developing greater nonmotor symptoms in PD. Understanding the increased risks of apathetic neuropsychiatric symptoms in people with moderate PD will lead to enhanced preventative and palliative treatments. In addition, providers must understand and identify signs of apathy within mild stages of PD because apathy is a predictive factor for parkinsonian decline, and cognitive decline over time.

Supplementary Materials: The following are available online at https: / www.mdpi.com/article / 10.3390/healthcare10010091/s1. Table S1: Comparison of Outcome variables between the Mild group and Moderate group.

Author Contributions: E.C. designed the project and wrote the paper. E.C., A.A.B. and other research lab assistants collected data, cross-checked data, administered assessments, and recruited participants. L.N. ran statistical analysis and created figures. E.C. and L.N. analyzed and interpreted data. M.E.H. administered the project as a whole, revised for intellectual content and gave the final approval. All authors have read and agreed to the published version of the manuscript.

Funding: This work was supported by the Parkinson's foundation (PF-0000049408, A7-2018Supplement, PF-CGP_19208_DREAM On.) and the United States Department of Veterans Affairs grant, 5IK2RX000870-06.

Institutional Review Board Statement: The Institutional Review Board at Emory University School of Medicine and the R\&D Committee of the Atlanta VA approved this work. Participants provided written informed consent before participating (IRB00080676; IRB00060613).

Informed Consent Statement: Participants provided written informed consent before participating (IRB00080676; IRB00060613).

Data Availability Statement: The data that support the findings of this study are available on request from the corresponding author. The data are not publicly available due to privacy or ethical restrictions.

Acknowledgments: This work was supported by the Parkinson's foundation (PF-0000049408, A72018-Supplement, PF-CGP_19208_DREAM On.) and the United States Department of Veterans Affairs grant, 5IK2RX000870-06. We would like to acknowledge and give thanks to all of the participants that were willing to participate in clinical trials to advance the understanding of PD related apathy and quality-of-life.

Conflicts of Interest: The authors declare no conflict of interest.

\section{References}

1. Pagonabarraga, J.; Kulisevsky, J. Apathy in Parkinson's Disease. Int. Rev. Neurobiol. 2017, 133, 657-678. [CrossRef] [PubMed]

2. Pagonabarraga, J.; Kulisevsky, J.; Strafella, A.P.; Krack, P. Apathy in Parkinson's Disease: Clinical features, neural substrates, diagnosis, and treatment. Lancet Neurol. 2015, 14, 518-531. [CrossRef]

3. Dujardin, K.; Sockeel, P.; Devos, D.; Delliaux, M.; Krystkowiak, P.; Destée, A.; Defebvre, L. Characteristics of Apathy in Parkinson's Disease. Mov. Disord. 2007, 22, 778-784. [CrossRef] [PubMed]

4. Thomsen, K.R.; Whybrow, P.C.; Kringelbach, M.L. Reconceptualizing anhedonia: Novel perspectives on balancing the pleasure networks in the human brain. Front. Behav. Neurosci. 2015, 9, 49. [CrossRef] 
5. $\quad$ Leentjens, A.F.G.; Dujardin, K.; Marsh, L.; Martinez-Martin, P.; Richard, I.H.; Starkstein, S.E.; Weintraub, D.; Sampaio, C.; Poewe, W.; Rascol, O.; et al. Apathy and anhedonia rating scales in Parkinson's disease: Critique and recommendations. Mov. Disord. 2008, 23, 2004-2014. [CrossRef] [PubMed]

6. Levy, R.; Dubois, B. Apathy and the functional anatomy of the prefrontal cortex-basal ganglia circuits. Cerebral Cortex 2006, 16, 916-928. [CrossRef]

7. Eslinger, P.J.; Damasio, A.R. Severe disturbances of higher cognition after bilateral frontal lobe ablation: Patient EVR. Neurology 1985, 35, 1731-1741. [CrossRef]

8. Pluck, G.C.; Brown, R.G. Apathy in Parkinson's disease. J. Neurol. Neurosurg. Psychiatry 2002, 73, 636-642. [CrossRef]

9. Czernecki, V.; Pillon, B.; Houeto, J.L.; Pochon, J.B.; Levy, R.; Dubois, B. Motivation, reward, and Parkinson's disease: Influence of dopatherapy. Neuropsychologia 2002, 40, 2257-2267. [CrossRef]

10. LeWitt, P.A.; Chaudhuri, K.R. Unmet needs in Parkinson disease: Motor and non-motor. Parkinsonism Relat. Disord. 2020, 80, S7-S12. [CrossRef]

11. Santangelo, G.; Barone, P.; Cuoco, S.; Raimo, S.; Pezzella, D.; Picillo, M.; Erro, R.; Moccia, M.; Pellecchia, M.T.; Amboni, M.; et al. Apathy in untreated, de novo patients with Parkinson's disease: Validation study of Apathy Evaluation Scale. J. Neurol. 2014, 261, 2319-2328. [CrossRef]

12. Prakash, K.M.; Nadkarni, N.V.; Lye, W.K.; Yong, M.H.; Tan, E.K. The impact of non-motor symptoms on the quality of life of Parkinson's disease patients: A longitudinal study. Eur. J. Neurol. 2016, 23, 854-860. [CrossRef] [PubMed]

13. den Brok, M.G.H.E.; van Dalen, J.W.; van Gool, W.A.; van Charante, E.P.M.; de Bie, R.M.A.; Richard, E. Apathy in Parkinson's disease: A systematic review and meta-analysis. Mov. Disord. 2015, 30, 759-769. [CrossRef]

14. Santangelo, G.; Vitale, C.; Trojano, L.; Picillo, M.; Moccia, M.; Pisano, G.; Pezzella, D.; Cuoco, S.; Erro, R.; Longo, K.; et al Relationship between apathy and cognitive dysfunctions in de novo untreated Parkinson's disease: A prospective longitudinal study. Eur. J. Neurol. 2015, 22, 253-260. [CrossRef]

15. Aarsland, D.; Larsen, J.P.; Lim, N.G.; Janvin, C.; Karlsen, K.; Tandberg, E.; Cummings, J.L. Range of neuropsychiatric disturbances in patients with Parkinson's disease. J. Neurol. Neurosurg. Psychiatry 1999, 67, 492-496. [CrossRef]

16. Starkstein, S.E.; Mayberg, H.S.; Preziosi, T.J.; Andrezejewski, P.; Leiguarda, R.; Robinson, R.G. Reliability, validity, and clinical correlates of apathy in Parkinson's disease. J. Neuropsychiatry Clin. Neurosci. 1992, 4, 134-139. [CrossRef]

17. Barone, P.; Antonini, A.; Colosimo, C.; Marconi, R.; Morgante, L.; Avarello, T.P.; Bottacchi, E.; Cannas, A.; Ceravolo, G.; Ceravolo, R.; et al. The PRIAMO study: A multicenter assessment of nonmotor symptoms and their impact on quality of life in Parkinson's disease. Mov. Disord. 2009, 24, 1641-1649. [CrossRef]

18. Starkstein, S.E.; Merello, M.; Jorge, R.; Brockman, S.; Bruce, D.; Power, B. The syndromal validity and nosological position of apathy in Parkinson's disease. Mov. Disord. 2009, 24, 1211-1216. [CrossRef]

19. Rodríguez-Violante, M.; González-Latapi, P.; Cervantes-Arriaga, A.; Martínez-Ramírez, D.; Velázquez-Osuna, S.; CamachoOrdoñez, A. Apathy and associated factors in Mexican patients with Parkinson's disease. Neurol. Sci. 2014, 35, 729-734. [CrossRef] [PubMed]

20. Ang, Y.; Lockwood, P.; Apps, M.A.J.; Muhammed, K.; Husain, M. Distinct subtypes of apathy revealed by the Apathy Motivation Index. PLoS ONE 2017, 12, e0169938. [CrossRef] [PubMed]

21. Marin, R.S.; Firinciogullari, S.; Biedrzycki, R.C. The sources of convergence between measures of apathy and depression. J. Affect. Disord. 1993, 28, 117-124. [CrossRef]

22. Marin, R.S.; Firinciogullari, S.; Biedrzycki, R.C. Group differences in the relationship between apathy and depression. J. Nerv. Ment. Dis. 1994, 182, 235-239. [CrossRef] [PubMed]

23. Le Heron, C.; Plant, O.; Manohar, S.; Yuem-Siang, A.; Jackson, M.; Lennox, G.; Hu, M.T.; Husain, M. Distinct effects of apathy and dopamine on effort-based decision-making in Parkinson's disease. Brain 2018, 141, 1455-1469. [CrossRef] [PubMed]

24. D’Iorio, A.; Vitale, C.; Piscopo, F.; Baiano, C.; Falanga, A.P.; Longo, K.; Amboni, M.; Barone, P.; Santangelo, G. Impact of anxiety, apathy and reduced functional autonomy on perceived quality of life in Parkinson's disease. Parkinsonism Relat. Disord. 2017, 43, 114-117. [CrossRef]

25. Hobson, P.; Holden, A.; Meara, J. Measuring the impact of Parkinson's disease with the Parkinson's Disease Quality of Life questionnaire. Age Ageing 1999, 28, 341-346. [CrossRef]

26. Szatmari, S.; Illigens, B.; Siepmann, T.; Pinter, A.; Takats, A.; Bereczki, D. Neuropsychiatric symptoms in untreated Parkinson's disease. Neuropsychiatr. Dis. Treat. 2017, 13, 815-826. [CrossRef]

27. Marsili, L.; Rizzo, G.; Colosimo, C. Diagnostic Criteria for Parkinson's Disease: From James Parkinson to the Concept of Prodromal Disease. Front. Neurol. 2018, 9, 156. [CrossRef]

28. Goldenberg, M.M. Medical management of Parkinson's disease. Pharm. Ther. 2008, 33, 590-606.

29. Goetz, C.G.; Poewe, W.; Rascol, O.; Sampaio, C.; Stebbins, G.T.; Counsell, C.; Giladi, N.; Holloway, R.G.; Moore, C.G.; Wenning, G.K.; et al. Movement Disorder Society Task Force report on the Hoehn and Yahr staging scale: Status and recommendations. Mov. Disord. 2004, 19, 1020-1028. [CrossRef]

30. Hoehn, M.M.; Yahr, M.D. Parkinsonism: Onset, progression, and mortality. Neurology 1967, 17, 427. [CrossRef]

31. Siu, A.L.; Reuben, D.B.; Hays, R.D. Hierarchical measures of physical function in ambulatory geriatrics. J. Am. Geriatr. Soc. 1990, 38, 1113-1119. [CrossRef] 
32. Rikli, R.E.; Jones, C.J. The reliability and validity of a 6-minute walk test as a measure of physical endurance in older adults. J. Aging Phys. Act. 1998, 6, 363-375. [CrossRef]

33. Giudicessi, J.R.; Ackerman, M.J. Determinants of incomplete penetrance and variable expressivity in heritable cardiac arrhythmia syndromes. Transl. Res. 2013, 161, 1-14. [CrossRef] [PubMed]

34. Goetz, C.G.; Tilley, B.C.; Shaftman, S.R.; Stebbins, G.T.; Fahn, S.; Martinez-Martin, M.; Poewe, W.; Sampaio, C.; Stern, M.B.; Dodel, R.; et al. Movement Disorder Society-sponsored revision of the Unified Parkinson's Disease Rating Scale (MDS-UPDRS): Scale presentation and clinimetric testing results. Mov. Disord. 2008, 23, 2129-2170. [CrossRef] [PubMed]

35. Damiano, A.M.; Snyder, C.; Strausser, B.; Willian, M.K. A review of health-related quality-of-life concepts and measures for Parkinson's disease. Qual. Life Res. 1999, 8, 235-243. [CrossRef] [PubMed]

36. Zahodne, L.B.; Young, S.; Kirsch-Darrow, L.; Nisenzon, A.; Fernandez, H.H.; Okun, M.S.; Bowers, D. Examination of the Lille Apathy Rating Scale in Parkinson disease. Mov. Disord. 2009, 24, 677-683. [CrossRef] [PubMed]

37. Levy, M.L.; Cummings, J.L.; Fairbanks, L.A.; Masterman, D.; Miller, B.L.; Craig, A.H.; Paulsen, J.S.; Litvan, I. Apathy is not depression. J. Neuropsychiatry Clin. Neurosci. 1998, 10, 314-319. [CrossRef] [PubMed]

38. Lopez, F.V.; Eglit, G.M.L.; Schiehser, D.M.; Pirogovsky-Turk, E.; Litvan, I.; Lessig, S.; Filoteo, J.V. Factor analysis of the Apathy Scale in Parkinson's disease. Mov. Disord. Clin. Pract. 2019, 6, 379-386. [CrossRef]

39. Mohammad, D.; Ellis, C.; Rau, A.; Ruthirakuhan, M.; Lanctot, K.L.; Herrmann, N. Psychometric properties of Apathy Scales in Parkinson's disease: A systematic review. Neurodegener. Dis. Manag. 2018, 8, 267-282. [CrossRef] [PubMed]

40. Clarke, D.E.; Ko, J.Y.; Kuhl, E.A.; van Reekum, R.; Salvador, R.; Marin, R.S. Are the available apathy measures reliable and valid? A review of the psychometric evidence. J. Psychosom. Res. 2011, 70, 73-97. [CrossRef]

41. Lang, A.E.; Eberly, S.; Goetz, C.G.; Stebbins, G.; Oakes, D.; Marek, K.; Ravina, B.; Tanner, C.M.; Shoulson, I.; LABS-PD investigators. Movement Disorder Society Unified Parkinson Disease Rating Scale experiences in daily living: Longitudinal changes and correlation with other assessments. Mov. Disord. 2013, 28, 1980-1986. [CrossRef]

42. Bernard, B.A.; Carns, D.; Stebbins, G.T.; Goldman, J.G.; Goetz, C.G. Relationship of Movement Disorders Society-Unified Parkinson's Disease Rating Scale Nonmotor symptoms to cognitive functioning in patients with Parkinson's disease. Mov. Disord. Clin. Pract. 2020, 7, 279-283. [CrossRef]

43. Weintraut, R.; Karádi, K.; Lucza, T.; Kovács, M.; Makkos, A.; Janszky, J.; Kovács, N. Lille Apathy Rating Scale and MDS-UPDRS for Screening Apathy in Parkinson's Disease. J. Parkinson's Dis. 2016, 6, 257-265. [CrossRef]

44. Aarsland, D.; Marsh, L.; Schrag, A. Neuropsychiatric symptoms in Parkinson's disease. Mov. Disord. 2009, 24, $2175-2186$. [CrossRef]

45. Johansson, P.; Riegel, B.; Svensson, E.; Brostrom, A.; Alehagen, U.; Dahlstrom, U.; Jaarsma, T. Sickness behavior in communitydwelling elderly. Biol. Res. Nurs. 2014, 16, 105-113. [CrossRef]

46. Liu, H.; Ou, R.; Wei, Q.; Hou, Y.; Zhang, L.; Cao, B.; Zhao, B.; Song, W.; Shang, H. Apathy in drug-naïve patients with Parkinson's disease. Parkinsonism Relat. Disord. 2017, 44, 28-32. [CrossRef]

47. Beck, A.T. An inventory for measuring depression. Arch. Gen. Psychiatry 1961, 4, 561-571. [CrossRef] [PubMed]

48. Beck, A.T.; Steer, R.A.; Garbin, M.G. Psychometric properties of the Beck Depression Inventory: Twenty-five years of evaluation. Clin. Psychol. Rev. 1998, 8, 77-100. [CrossRef]

49. Cuoco, S.; Cappiello, A.; Abate, F.; Tepedino, M.F.; Erro, R.; Volpe, G.; Pellecchia, M.T.; Barone, P.; Picillo, M. Psychometric properties of the Beck Depression Inventory-II in progressive Supranuclear Palsy. Brain Behav. 2021, 11, e2344. [CrossRef] [PubMed]

50. Nasreddine, Z.S.; Phillips, N.A.; Bédirian, V.; Charbonneau, S.; Whitehead, V.; Collin, I.; Cummings, J.L.; Chertkow, H. The Montreal Cognitive Assessment, MoCA: A brief screening tool for mild cognitive impairment. J. Am. Geriatr. Soc. 2005, 53, 695-699. [CrossRef]

51. Tomlinson, C.L.; Stowe, R.; Patel, S.; Rick, C.; Gray, R.; Clarke, C.E. Systematic review of levodopa dose equivalency reporting in Parkinson's disease. Mov. Disord. 2010, 25, 2649-2653. [CrossRef] [PubMed]

52. Martin, G.P.; McDonald, K.R.; Allsop, D.; Diggle, P.J.; Leroi, I. Apathy as a behavioural marker of cognitive impairment in Parkinson's disease: A longitudinal analysis. J. Neurol. 2020, 267, 214-227. [CrossRef] [PubMed]

53. Baggio, H.C.; Segura, B.; Garrido-Millan, J.L.; Marti, M.J.; Compta, Y.; Valldeoriola, F.; Tolosa, E.; Junque, C. Resting-state frontostriatal functional connectivity in Parkinson's disease-related apathy. Mov. Disord. 2015, 30, 671-679. [CrossRef] [PubMed]

54. Harpham, W.S. Resolving the frustration of fatigue. CA Cancer J. Clin. 1999, 49, 178-189. [CrossRef]

55. van Hooff, M.L.M.; Geurts, S.A.E.; Beckers, D.G.J.; Kompier, M.A.J. Daily recovery from work: The role of activities, effort and pleasure. Work Stress 2011, 25, 55-74. [CrossRef]

56. Zhou, Z.; Müller, M.L.T.M.; Kanel, P.; Chua, J.; Kotagal, V.; Kaufer, D.I.; Albin, R.L.; Frey, K.A.; Bohnen, N.I. Apathy rating scores and $\beta$-amyloidopathy in patients with Parkinson disease at risk for cognitive decline. Neurology 2020, 94, e376-e383. [CrossRef] [PubMed]

57. Shah, N.; Frey, K.A.; Müller, M.L.; Petrou, M.; Kotagal, V.; Koeppe, R.A.; Scott, P.J.; Albin, R.L.; Bohnen, N.I. Striatal and Cortical $\beta$-Amyloidopathy and cognition in Parkinson's disease. Mov. Disord. 2016, 31, 111-117. [CrossRef]

58. Husain, M.; Roiser, J.P. Neuroscience of apathy and anhedonia: A transdiagnostic approach. Nat. Rev. Neurosci. 2018, 19, 470-484. [CrossRef] 
59. Santangelo, G.; Vitale, C.; Trojano, L.; Longo, K.; Cozzolino, A.; Grossi, D.; Barone, P. Relationship between depression and cognitive dysfunctions in Parkinson's disease without dementia. J. Neurol. 2009, 256, 632-638. [CrossRef]

60. Ehrt, U.; Brønnick, K.; Leentjens, A.F.G.; Larsen, J.P.; Aarsland, D. Depressive symptom profile in Parkinson's disease: A comparison with depression in elderly patients without Parkinson's disease. Int. J. Geriatr. Psychiatry 2006, 21, 252-258. [CrossRef]

61. Pedersen, K.F.; Larsen, J.P.; Alves, G.; Aarsland, D. Prevalence and clinical correlates of apathy in Parkinson's disease: A community-based study. Parkinsonism Relat. Disord. 2009, 15, 295-299. [CrossRef]

62. Cramer, C.K.; Friedman, J.H.; Amick, M.M. Olfaction and apathy in Parkinson's disease. Parkinsonism Relat. Disord. 2010, 16, 124-126. [CrossRef]

63. Politis, M.; Wu, K.; Molloy, S.; Bain, P.G.; Chaudhuri, K.R.; Piccini, P. Parkinson's disease symptoms: The patient's perspective. Mov. Disord. 2010, 25, 1646-1651. [CrossRef] [PubMed]

64. Dickerson, A.E.; Molnar, L.J.; Eby, D.W.; Alder, G.; Bedard, M.; Berg-Weger, M.; Classen, S.; Foley, D.; Horowitz, A.; Kerschner, H.; et al. Transportation and Aging: A Research Agenda for Advancing Safe Mobility. Gerontologist 2007, 47, 578-590. [CrossRef] [PubMed]

65. Kaplan, G.A. Where do shared pathways lead? Some reflections on a research agenda. Psychosom. Med. 1995, 57, 208-212. [CrossRef] [PubMed]

66. Yassuda, M.S.; Wilson, J.J.; von Mering, O. Driving Cessation: The Perspective of senior drivers. Educ. Gerontol. 1997, 23, 525-538 [CrossRef]

67. Spadaro, L.; Bonanno, L.; Di Lorenzo, G.; Bramanti, P.; Marino, S. Health-related quality of life in Parkinson's disease in northeastern Sicily, Italy: (An ecological perspective). Neural Regen. Res. 2013, 8, 1615-1622. [CrossRef] [PubMed]

68. Hariz, G.M.; Forsgren, L. Activities of daily living and quality of life in persons with newly diagnosed Parkinson's disease according to subtype of disease, and in comparison to healthy controls. Acta Neurol. Scand. 2010, 123, 20-27. [CrossRef]

69. Owsley, C.; McGwin, G. Vision impairment and driving. Surv. Ophthalmol. 1999, 43, 535-550. [CrossRef]

70. Dahan-Oliel, N.; Mazer, B.; Gelinas, I.; Dobbs, B.; Lefebvre, H. Transportation use in community dwelling older adults: Association with participation and leisure activities. Can. J. Aging 2010, 29, 491-502. [CrossRef]

71. Dobbs, B.M.; Carr, D. Screening and assessment of medically at-risk drivers. Public Policy Aging Rep. 2005, 15, 6-12. [CrossRef]

72. Brennan, L. Dopaminergic Therapy in Parkinson's Disease: Psychiatric Symptoms, Cognition, and Everyday Functioning. Diss. Abstr. Int. Sect. B Sci. Eng. 2014, 74. Available online: https:/ / ovidsp.ovid.com/ovidweb.cgi?T=JS\&PAGE=reference\&D=psyc1 $1 \& N E W S=N \& A N=2014-99060-157$ (accessed on 5 May 2021).

73. Karlsen, K.; Larsen, J.P.; Tandberg, E.; Jørgensen, K. Fatigue in patients with Parkinson's disease. Mov. Disord. 1999, 14, $237-241$. [CrossRef]

74. Cubo, E.; Benito-León, J.; Coronell, C.; Armesto, D. Clinical correlates of apathy in patients recently diagnosed with Parkinson's disease: The ANIMO Study. Neuroepidemiology 2012, 38, 48-55. [CrossRef] [PubMed]

75. Schifitto, G.; Friedman, J.H.; Oakes, D.; Shulman, L.; Comella, C.L.; Marek, K.; Fahn, S.; Parkinson Study Group ELLDOPA Investigators. Fatigue in levodopa-naive subjects with Parkinson disease. Neurology 2008, 71, 481-485. [CrossRef] [PubMed]

76. Pedersen, K.F.; Larsen, J.P.; Aarsland, D. Validation of the Unified Parkinson's Disease Rating Scale (UPDRS) section I as a screening and diagnostic instrument for apathy in patients with Parkinson's disease. Park Relat. Disord. 2008, 14, 183-186. [CrossRef] [PubMed]

77. Varanese, S.; Perfetti, B.; Ghilardi, M.F.; Di Rocco, A. Apathy, but not depression, reflects inefficient cognitive strategies in Parkinson's disease. PLoS ONE 2011, 6, e17846. [CrossRef] [PubMed]

78. McKinlay, A.; Grace, R.C.; Dalrymple-Alford, J.C.; Anderson, T.J.; Fink, J.; Roger, D. Neuropsychiatric problems in Parkinson's disease: Comparisons between self and caregiver report. Aging Ment. Health 2008, 12, 647-653. [CrossRef] 